\title{
CARACTERÍSTICAS FÍSICAS E FÍSICO-QUÍMICAS DE UM TIPO DE BACURI (Platonia insignis Mart.) COM RENDIMENTO INDUSTRIAL SUPERIOR ${ }^{1}$
}

\author{
JOSÉ EDMAR URANO DE CARVALHO ${ }^{2}$, RAIMUNDA FÁTIMA RIBEIRO DE NAZARÉ, WALNICE MARIA OLIVEIRA \\ DO NASCIMENTO ${ }^{4}$
}

\begin{abstract}
RESUMO - Efetuou-se a caracterização física do fruto e físico-química da polpa do bacuri CPATU 207-3, oriundo de uma planta-matriz do Banco de Germoplasma de Bacurizeiro da Embrapa Amazônia Oriental. Para a caracterização física foi utilizada uma amostra de 50 frutos, os quais foram individualmente analisados quanto aos seguintes aspectos: cor do epicarpo, formato, peso, comprimento, diâmetro, espessura da casca, volume da cavidade interna, número de sementes e de segmentos partenocárpicos, rendimentos porcentuais (p/p) de casca, polpa, sementes e do conjunto representado pela coluna placentária e óvulos abortados. A caracterização físico-química foi efetuada em três amostras de polpa congelada a $18^{\circ} \mathrm{C}$ negativos, provenientes de frutos em completo estádio de maturação, coletados nos meses de janeiro, fevereiro e março de 2001, tendo sido consideradas as seguintes variáveis: teores de umidade, de sólidos totais e de sólidos solúveis totais ( $\left.{ }^{\circ} \mathrm{Brix}\right)$, $\mathrm{pH}$, acidez total e a relação sólidos solúveis totais/acidez total titulável. O bacuri CPATU 207-3 apresentou formato ovalado e com ápice ligeiramente pontiagudo, epicarpo de coloração amarelada, fruto de tamanho considerado médio e peso médio de $265,8 \mathrm{~g}$. As principais características diferenciais desse tipo de bacuri são: a espessura da casca $(0,75 \mathrm{~cm})$, o rendimento porcentual de polpa $(27,7 \%)$ e o número de segmentos partenocárpicos $(2,8$ unidades/fruto). A polpa do bacuri CPATU 207-3 apresentou boas características físico-químicas, com 84,35\% de umidade, 15,65\% de sólidos totais, teor de sólidos solúveis totais de $14,53^{\circ}$ Brix, $\mathrm{pH} 3,34$, acidez total titulável de 1,24\% e relação ${ }^{\circ}$ Brix/acidez total titulável igual a 11,4. As características físicas e físico-químicas desse tipo de bacuri permitem sua utilização tanto para consumo na forma de fruta fresca como na forma industrializada. Nesse último caso, é particularmente indicado para fabricação de compota, em decorrência do elevado número de segmentos partenocárpicos que apresenta.
\end{abstract}

Termos para indexação: fruto tropical, composição centesimal, sólidos solúveis.

\section{PHYSICAL AND PHYSICOCHEMICAL CHARACTERISTICS OF A BACURI (Platonia insignis Mart.) TYPE WITH BETTER INDUSTRIAL} YIELD

ABSTRACT - Physical and physicochemical characterization were carried out on bacuri CPATU 207-3, originated from a mother-plant of the Germplasm Bank of Embrapa Amazônia Oriental. Fifty fruits were used for the physical characterization. Each fruit was characterized on the following aspects: color of the epicarp, shape, weight, length, diameter, thickness of the shell and the relative proportion (w/w) of the shell, pulp, seeds and the structure represented by the placental column and aborted ovules. The physicochemical characterization was conducted on three samples of the freezing pulp, derived from mature fruits collected, in 2001 in January, February and March. The following characteristics were determined: moisture content, total solids, total soluble solids ( $\left.{ }^{\circ} \mathrm{Brix}\right), \mathrm{pH}$, titratable total acidity, and the ratio between ${ }^{\circ}$ Brix and total acidity. The bacuri CPATU 207-3 showed an ovate shape, with acuminate apex, yellow color, medium size and mean weight of $265.8 \mathrm{~g}$. The main differential characteristics of this bacuri type are: thin shell $(0.75 \mathrm{~cm})$, the percentual yield pulp $(27.7 \%)$ and the number of the parthenocarpic section (2.8). The pulp had good physicochemical characteristics, with $84.35 \%$ moisture content, $15.65 \%$ total solids, $14,53^{\circ}$ Brix total soluble solids, $\mathrm{pH} 3.34$ and titratable total acidity $1.24 \%$. The total soluble solids to total acidity ratio was 11.4. The physical and physicochemical characteristics of bacuri CPATU 207-3, allow its consumption in form of fresh fruit or in industrialized form. In this last case, it is particularly suitable for compote production, due to the high number of parthenocarpic segments.

Index terms: tropical fruit, centesimal composition, soluble solids.

O fruto do bacurizeiro é uma baga uniloculada, com formato arredondado, ovalado ou achatado (Cavalcante, 1996, Guimarães et al., 1992), contendo em seu interior de uma a cinco sementes envolvidas pelo endocarpo, que se constitui na parte comestível do fruto (Carvalho et al. 1998, Mourão \& Beltrati, 1995a/1995b). Alguns tipos, de ocorrência rara, apresentam frutos desprovidos de sementes (Calzavara, 1970; Souza et al., 2000), os quais têm despertado pouco interesse, pois apresentam tamanho diminuto e baixo teor de sólidos solúveis totais na polpa (Carvalho et al., 2002).

O bacuri é oriundo de ovário pentaloculado, com número de óvulos por lóculo variando entre oito e quatorze (Guimarães et al., 1990; Maués \& Venturieri, 1996). Quando nenhum dos óvulos, em um ou mais lóculos, é convertido em semente, ocorre a formação de segmentos partenocárpicos, popularmente denominados de filhos ou línguas, que se constituem na porção preferida da polpa, por não estar aderida às sementes e ser de fácil remoção (Cavalcante, 1996).

Em termos porcentuais, a maior parte do bacuri é constituída pelo epicarpo e mesocarpo, os quais, em conjunto, constituem a casca do fruto, que é de consistência rígido-coriácea e com espessura variando entre 0,7 cm e 2,0 cm (Santos, 1982; Guimarães et al., 1992; Cavalcan- te, 1996). Em média, a casca representa $64 \%$ a $70 \%$ do peso do fruto, vindo a seguir as sementes, cuja participação varia de $13 \%$ a $26 \%$. A polpa é o componente que se apresenta em menor proporção, representando somente cerca de $10 \%$ a $18 \%$ do peso do fruto (Calzavara, 1970; Barbosa et al., 1979; Santos, 1982; Cruz, 1988; Guimarães et al., 1992; Teixeira, 2000).

O objetivo deste trabalho foi caracterizar um tipo de bacuri que apresenta rendimento porcentual de polpa bem superior ao da maioria dos tipos ocorrentes em populações nativas e em áreas de cultivo.

Os frutos foram provenientes da matriz CPATU 207-3, do Banco de Germoplasma de Bacurizeiro da Embrapa Amazônia Oriental, localizado no município de Tomé-Açu, PA. Essa matriz constitui-se em um dos indivíduos do acesso CPATU 10007, estabelecido na forma de progênies de meios-irmãos. A planta-matriz que deu origem ao acesso apresentava frutos com formato arredondado, peso médio de 267,56 g, espessura da casca de $1,15 \mathrm{~cm}$ e rendimento porcentual de polpa de $6,88 \%$ (Guimarães et al., 1992).

Para a caracterização física utilizou-se uma amostra de 50 frutos, os quais foram individualmente analisados quanto às seguintes características: coloração, formato, peso, comprimento, diâmetro, es-

\footnotetext{
${ }^{1}$ (Trabalho 025/2002). Recebido: 07/03/2002. Aceito para publicação: 30/04/2003.

${ }^{2}$ Mestre em Agronomia, Área de Produção Vegetal, Pesquisador da Embrapa Amazônia Oriental. Caixa Postal 48. CEP 66095-110, Belém, PA. E-mail: urano@cpatu.embrapa.br.

${ }_{3}^{3}$ Mestre em Tecnologia de Alimentos, Pesquisadora da Embrapa Amazônia Oriental. Caixa Postal 48. CEP 66095-110, Belém, PA. E-mail: fatima@ cpatu.embrapa.br. ${ }^{4}$ Mestre em Tecnologia de Sementes, Pesquisadora da Embrapa Amazônia Oriental. Caixa Postal 48. CEP 66095-110, Belém, PA. E-mail: walnice@ @patu.embrapa.br.
} 


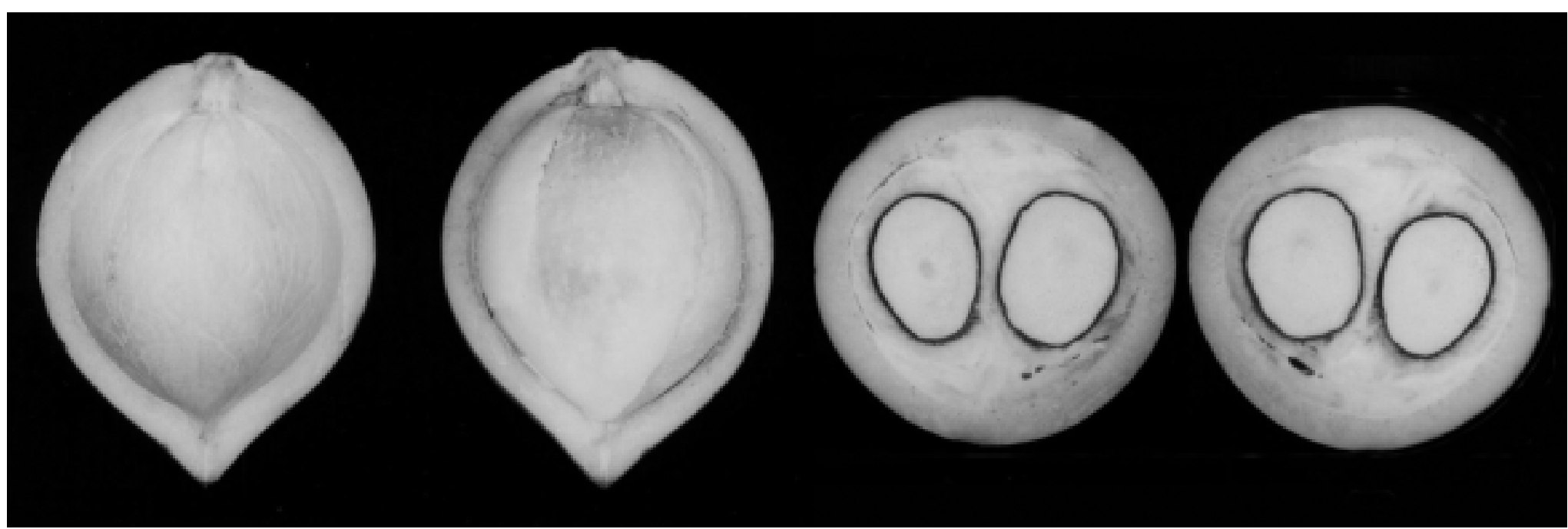

FIGURA 1 - Seções longitudinais e transversais do bacuri CPATU 207-3.

pessura da casca, volume da cavidade interna, número de sementes por fruto, número de segmentos partenocárpicos, rendimentos porcentuais de casca, polpa total, sementes e do conjunto representado pela coluna placentária e óvulos abortados. A polpa total foi fracionada em duas porções: polpa aderida às sementes e segmentos partenocárpicos.

As características físico-químicas da polpa foram determinadas com base em três amostras de polpa, oriundas, cada uma delas, de 25 frutos coletados nos meses de janeiro, fevereiro e março. As seguintes características foram avaliadas: teores de umidade e de sólidos totais, determinados pela secagem da amostra em estufa a $105^{\circ} \mathrm{C}$ até peso constante; $\mathrm{pH}$, valor obtido pela leitura da solução de amostra em aparelho pH-meter digital marca HORIBA F-21; acidez total titulável, quantificada pelo método titulométrico com solução de $\mathrm{NaOH} 0,1 \mathrm{~N}$ fatorada, usando como indicador solução de fenolftaleína a 1\%; sólidos solúveis totais, determinado pela leitura direta da solução de amostra diluída com fator conhecido, em aparelho refratômetro digital, marca ATAGO modelo PR-101 e a relação ${ }^{\circ}$ Brix / acidez total titulável.

Observou-se que o bacuri CPATU 207-3 apresenta epicarpo de cor amarela, quando completamente maduro, formato ovalado, com a extremidade apical ligeiramente pontiaguda (Figura 1a) e grande freqüência de frutos com no máximo duas sementes (Figura 1b). Com relação ao tamanho, peso e volume da cavidade interna, os frutos são semelhantes ao da maioria dos tipos ocorrentes em populações naturais e em áreas de cultivo, podendo ser enquadrados no grupo de bacuris de tamanho médio, os quais são bem aceitos no mercado e apresentam peso variando entre $250 \mathrm{~g}$ e $350 \mathrm{~g}$. As principais características diferenciais do bacuri CPATU 207-3, em relação à maioria dos tipos ocorrentes em populações naturais e em áreas de cultivo, são: casca fina, elevado número de segmentos partenocárpicos e rendimento porcentual de polpa superior. A espessura da casca, apenas $0,75 \mathrm{~cm}$, é bem inferior à da maioria dos tipos de bacuri que, predominantemente, apresentam casca com espessura superior a $1,0 \mathrm{~cm}$, em alguns genótipos chegando mesmo a atingir 2,0 cm (Santos, 1982; Cavalcante, 1996; Guimarães et al., 1992). Essa característica é a principal responsável pelo elevado rendimento porcentual de polpa $(27,7 \%)$, pois condiciona menor participação relativa da casca na composição do fruto. Esse fato fica bem evidenciado quando se considera o rendimento porcentual de sementes, $18,7 \%(\mathrm{Ta}-$ bela 1), que está dentro dos limites assinalados na literatura (Calzavara, 1970; Barbosa et al., 1979; Cruz, 1988; Santos, 1982; Guimarães, 1992; Teixeira, 2000).

No que concerne à partição da polpa, constatou-se que os rendimentos porcentuais das frações polpa aderida às sementes e segmentos partenocárpicos se equivaleram (Figura 2). Isoladamente, o rendimento porcentual de segmentos partenocárpicos, em torno de 13,0\%, foi igual e, em alguns casos, mesmo superior ao rendimento porcentual total de polpa de muitos tipos de bacuri (Calzavara, 1970, Cruz, 1979; Barbosa et al., 1979; Guimarães et al., 1992). O elevado rendimento porcentual da fração da polpa representada pelos segmentos partenocárpicos está associada à grande frequiência de frutos contendo no máximo duas sementes, pois foi constatada correlação negativa entre o número de sementes e o número desses segmentos $(\mathrm{r}=-0,9012)$. A elevada proporção de segmentos partenocárpicos é uma característica desejável, pois essa porção da polpa é a que tem maior valor comercial. Além disso, sua presença, em proporções elevadas, é altamente desejável quando os frutos se destinam ao consumo como fruta fresca ou para a elaboração de compotas.

TABELA 1 - Valores médios, mínimos e máximos de características físicas do bacuri CPATU 207-3

\begin{tabular}{|c|c|c|c|c|}
\hline Característica & \multicolumn{2}{|c|}{ Média $^{1}$} & Mínimo & Máximo \\
\hline Peso (g) & 265,8 & $( \pm 52,1)$ & 161,6 & 374,7 \\
\hline Comprimento $(\mathrm{cm})$ & 10,09 & $( \pm 0,81)$ & 7,31 & 11,52 \\
\hline Diâmetro $(\mathrm{cm})$ & 7,55 & $( \pm 0,55)$ & 6,24 & 8,35 \\
\hline Espessura da casca $(\mathrm{cm})$ & 0,75 & $( \pm 0,08)$ & 0,60 & 0,95 \\
\hline $\begin{array}{l}\text { Volume da cavidade } \\
\text { interna }\left(\mathrm{cm}^{3}\right)\end{array}$ & 128,8 & $( \pm 28,1)$ & 76 & 186 \\
\hline $\begin{array}{l}\text { Sementes por fruto } \\
\text { (número) }\end{array}$ & 2,3 & $( \pm 0,7)$ & 1 & 4 \\
\hline $\begin{array}{l}\text { Segmentos partenocárpicos } \\
\text { por fruto (número) }\end{array}$ & 2,8 & $( \pm 0,6)$ & 2 & 4 \\
\hline Casca $(\%)$ & 53,3 & $( \pm 1,9)$ & 48,9 & 57,3 \\
\hline Polpa (\%) & 27,7 & $( \pm 2,4)$ & 22,3 & 32,9 \\
\hline Semente $(\%)$ & 18,7 & $( \pm 3,3)$ & 10,8 & 25,1 \\
\hline $\begin{array}{l}\text { Coluna pla centária e } \\
\text { óvulos abortados }(\%)\end{array}$ & 0,3 & $( \pm 0,1)$ & 0,2 & 0,4 \\
\hline
\end{tabular}

1. Valores representam médias ( \pm desvio padrão), $\mathrm{n}=5$.

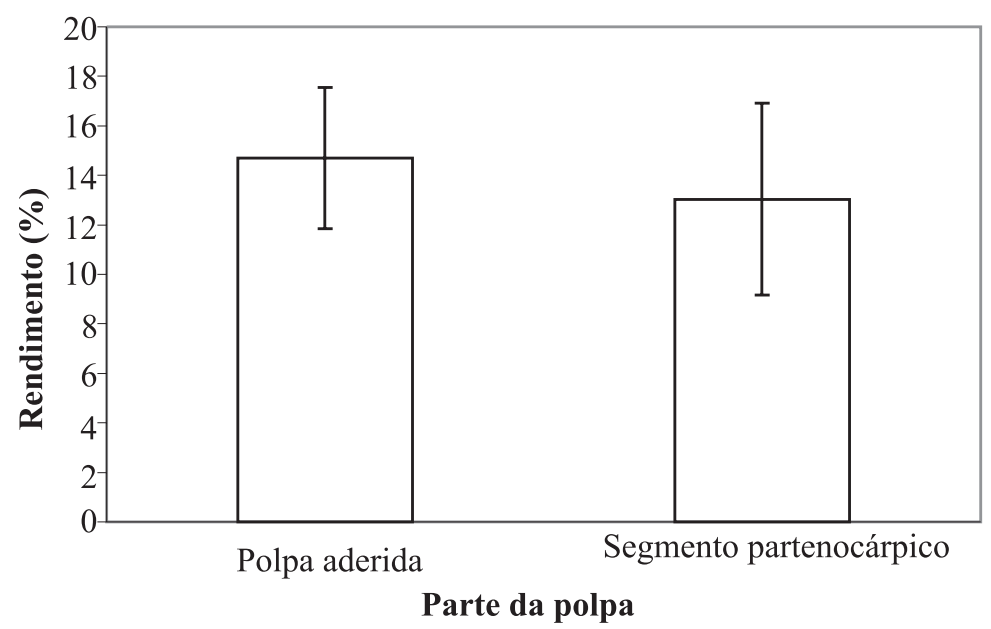

FIGURA 2 - Rendimentos porcentuais das frações representadas pela polpa aderida às sementes e pelos segmentos partenocárpicos no bacuri CPATU 207-3 (Valores representam médias \pm desvio padrão, $\mathrm{n}=50$ frutos). 
As variações entre as características físicas dos frutos da planta-mãe (Guimarães et al., 1992) e de sua descendente, a matriz CPATU 207-3, principalmente em relação à espessura da casca, formato do fruto e rendimento porcentual de polpa foram bem pronunciadas. Tal fato é decorrente de que a espécie é essencialmente alógama, por ser geneticamente auto-incompatível (Maués \& Venturieri, 1996).

Os resultados concernentes às características físico-químicas da polpa, oriunda de frutos produzidos em janeiro, fevereiro e março, demonstraram que praticamente não houve variação na qualidade dos frutos do bacuri CPATU 207-3, em função da época de produção (Tabela 2).

TABELA 2 - Características físico-químicas da polpa do bacuri CPATU 207-3, oriunda de frutos produzidos nos meses de janeiro, fevereiro e março.

\begin{tabular}{|c|c|c|c|c|c|c|}
\hline $\begin{array}{l}\text { Época de } \\
\text { produção }\end{array}$ & $\begin{array}{c}\text { Umidade } \\
(\%)\end{array}$ & $\begin{array}{c}\text { Sólidos } \\
\text { totais } \\
(\%)\end{array}$ & $\begin{array}{c}\text { Sólidos } \\
\text { solúveis } \\
\left({ }^{\circ} \text { Brix) }\right.\end{array}$ & $\mathrm{pH}$ & $\begin{array}{c}\text { Acidez } \\
\text { total } \\
(\%)\end{array}$ & $\begin{array}{c}\text { Relação } \\
{ }^{\circ} \text { Brix } \\
\text { /acidez } \\
\end{array}$ \\
\hline Janeiro & 84,09 & 15,91 & 14,6 & 3,26 & 1,34 & 11,0 \\
\hline Fevereiro & 84,14 & 15,86 & 14,7 & 3,47 & 1,13 & 13,0 \\
\hline Março & 84,81 & 15,19 & 14,3 & 3,30 & 1,25 & 11,4 \\
\hline Média & 84,35 & 15,65 & 14,5 & 3,34 & 1,24 & 11,4 \\
\hline C.V. $(\%)$ & 0,47 & 2,57 & 1,4 & 3,34 & 8,50 & 8,97 \\
\hline
\end{tabular}

Os valores para teor de umidade, nas três amostras consideradas, foram superiores aos valores encontrados por Santos (1982) e Teixeira (2000) em polpa oriunda de frutos produzidos no Estado do Piauí, mas compatíveis com as determinações efetuadas por Guimarães et al. (1992) e por Barbosa et al. (1979) em polpa de frutos produzidos no Estado do Pará. No que concerne às demais características, com exceção da acidez e da relação sólidos solúveis totais/acidez total titulável, onde Teixeira (2000) verificou valores entre $0,32 \%$ e $0,43 \%$ e entre 43,87 e 56,84 , respectivamente, os resultados estão dentro dos limites comumente registrados na literatura. Convém ressaltar, no entanto, que em relação à acidez total existem grandes variações, em função do genótipo (Guimarães, 1992).

O bacuri CPATU 207-3 apresenta características físicas e físico-químicas que permitem sua utilização tanto como fruta fresca quanto como fruta industrial. Nesse último caso, é particularmente indicado para a elaboração de compotas pois apresenta elevado rendimento de segmentos partenocárpicos.

\section{REFERÊNCIAS}

BARBOSA, W. C.; NAZARÉ, R. F. R. de; NAGATA, I. Estudo físicos e químicos dos frutos: bacuri (Platonia insignis), cupuaçu (Theobroma grandiflorum) e muruci (Byrsonima crassifolia). In: CONGRESSO BRASILEIRODE FRUTICULTURA, 2., 1979, Pelotas. Anais...Pelotas: SBF, 1979. v.2, p.797-808.
CALZAVARA, B.B.G. Fruteiras: abieiro, abricozeiro, bacurizeiro, cupuaçuzeiro. Belém: IPEAN. v. 1, n2, 84p. 1970 (Série Culturas da Amazônia)

CARVALHO, J.E.U. de; NASCIMENTO, W.M.O. do; MÜLLER, C.H. Características físicas e de germinação de sementes de espécies frutíferas nativas da Amazônia. Belém: Embrapa Amazônia Oriental, 1998. 18p. (Boletim de Pesquisa,203).

CARVALHO, J.E.U. de; NASCIMENTO, W.M.O. do; MÜLLER, C.H.Características físicas e químicas de um tipo de bacuri (Platonia insignis Mart.) sem sementes. Revista Brasileira de Fruticultura, Jaboticabal, v.24, n.2, p. 573-57518, 2002.

CAVALCANTE, P.B. Frutas comestíveis da Amazônia. 6ed. Belém: CNPq/ Museu Paraense Emílio Goeldi, 1996. 279p. (Coleção Adolpho Ducke).

CRUZ, P. E. N. Caracterização química e nutricional de algumas frutas do Estado do Maranhão. São Luís: U.F.Ma, 1988. 58f. Tese (Titular Química de Alimentos) - Universidade Federal do Maranhão, São Luis, 1988.

GUIMARÃES, A.D.G.; CARRERA, L.M.M.; NEVES, M. do P.H. das; MOTA, M.G. da C.; NASCIMENTO, T.B. do; MÜLLER, C.H.; PADILHA, N.C.C. Sistema reprodutivo do bacurizeiro (Platonia insignis Mart.). In: RELATÓRIO TÉCNICO ANUAL DO CENTRO DE PESQUISA AGROPECUÁRIA DO TRÓPICO ÚMIDO, 1990. Belém: Embrapa-CPATU, 1990. p. 91-99.

GUIMARÃES, A.D.G.; MOTA, M.G. da C.; NAZARÉ, R.F.R. de. Coleta de germoplasma de bacuri (Platonia insignis Mart.) na Amazônia. I. Microrregião Campos do Marajó (Soure/Salvaterra). Belém: Embrapa-CPATU, 1992. 23p. (Boletim de Pesquisa, 132).

MAUÉS, M.M.; VENTURIERI, G.C. Ecologia da polinização do bacurizeiro (Platonia insignis Mart.) Clusiaceae. Belém: EmbrapaCPATU, 1996. 24p. (Boletim de Pesquisa, 170).

MOURÃO, K.S.M.; BELTRATI, C.M. Morfologia dos frutos, sementes e plântulas de Platonia insignis Mart. (Clusiaceae). I. Aspectos anatômicos dos frutos e sementes em desenvolvimento. Manaus: Acta Amazônica, Manaus, v.25, n.1/2, p.11-31, 1995a.

MOURÃO, K.S.M.; BELTRATI, C.M. Morfologia dos frutos, sementes e plântulas de Platonia insignis Mart. (Clusiaceae). II. Morfo-anatomia dos frutos e sementes maduras. Manaus: Acta Amazônica, Manaus, v.25, n.1/2, p.47-53, 1995 b.

SANTOS. M. do S.S.A. Caracterização física, química e tecnológica do bacuri (Platonia insignis Mart.) e seus produtos. 1982.63f. Tese (Mestrado) - Universidade Federal do Ceará, Fortaleza, 1982.

SOUZA, V.A.B.de; VASCONCELOS, L.F.L.; ARAÚJO, E.C.E.; ALVES, R.E. Bacurizeiro (Platonia insignis Mart.). Jaboticabal: FUNEP, 2000. 72p. (Série Frutas Nativas, 11).

TEIXEIRA, G.H. de A. Frutos do bacurizeiro (Platonia insignis Mart.): caracterização, qualidade e conservação. 2000. 106f. Dissertação (Mestrado) - Faculdade de Ciências Agrárias e Veterinárias, Jaboticabal, Universidade Estadual Paulista. 